An experimental study of flame and autoignition interactions of iso-octane and air mixtures

Dimitris Assanis $^{\text {a,*, }}$, Scott W. Wagnon ${ }^{\mathrm{a}}$, and Margaret S. Wooldridge $\mathrm{a}^{\mathrm{a}, \mathrm{b}}$

${ }^{a}$ Department of Mechanical Engineering, University of Michigan, Ann Arbor, Michigan 48109-2125, USA

${ }^{b}$ Department of Aerospace Engineering, University of Michigan, Ann Arbor, MI 48109-2125, USA

* Corresponding author:

Dimitris Assanis

University of Michigan

Department of Mechanical Engineering

2350 Hayward Street, Ann Arbor, Michigan, USA 48109-2125

Fax: 734-647-3170, Voice: 734-763-7470

E-mail address: dassanis@umich.edu

Type of article: Full length 


\title{
An experimental study of flame and autoignition interactions of $i$ so-octane and air mixtures
}

\author{
Dimitris Assanis, Scott W. Wagnon, and Margaret S. Wooldridge
}

\begin{abstract}
Recent modifications to the University of Michigan rapid compression facility (UM RCF) were made to allow direct imaging of flame/autoignition interactions using compression to initiate autoignition chemistry and a spark plug to initiate simultaneous flame development. The experimental data in this study quantify the effects of spark-initiated flame propagation on autoignition of $i s o$-octane $/ \mathrm{O}_{2} /$ inert gas mixtures at well-defined initial conditions. The work leveraged the controlled environment of the $\mathrm{UM} \mathrm{RCF}$, in which temperature, pressure, and composition are nominally uniform and well-known at the end of compression. Flame initiation by the spark plasma, flame propagation, and autoignition were monitored using high-speed optical imaging of chemiluminescence and in situ pressure time histories. End-of-compression temperatures from $T_{E O C}=942-1018 \mathrm{~K}$ were considered, while the end-of-compression pressures were nominally constant within the range of $P_{E O C}=7.8-9.5 \mathrm{~atm}$. The fuel-to- $\mathrm{O}_{2}$ molar equivalence ratio was varied from $\phi=0.20-0.99$ and dilution, defined as the molar ratio of inert gases to $\mathrm{O}_{2}$ in the reactant mixture, was varied from inert: $\mathrm{O}_{2}=3.76-$ 7.47 to determine the effects on flame/autoignition interactions as well as to identify the lean flammability limit of the mixtures as a function of dilution. Flame propagation is generally expected to decrease autoignition delay times by compression heating the unburned portion of the mixture. The effect of flame propagation was maximized in these experiments by igniting the mixtures early during the autoignition process. Later spark timings had small to negligible effect on the autoignition delay time. Dilution had significant effect on the lean flammability limits, increasing from a lean limit of $\phi=0.35$ at air levels of dilution to $\phi=0.65$ at inert: $\mathrm{O}_{2}$
\end{abstract}


dilution of 7.5. The flammability limit was well correlated with the theoretical adiabatic flame temperature of each experiment. The propagation rates of flames successfully initiated by the spark plasma were determined from the imaging data and were $\sim 1-12 \mathrm{~m} / \mathrm{s}$. The magnitude of the propagation rates and the effect on the time integrated temperature scaled with the energy content of the mixtures as indicated by the theoretical adiabatic flame temperature.

Keywords: iso-octane; flame propagation; autoignition; spark; rapid compression facility; imaging 


\section{Introduction}

Advanced modes of internal combustion (IC) engine operation have potential to dramatically improve IC engine efficiencies while simultaneously lowering engine emissions $[1,2,3,4,5]$. Advanced engine operating strategies include low temperature and fuel lean conditions, which enable higher compression ratios and may reduce the need for exhaust gas after-treatment [2-5]. Homogeneous charge compression ignition (HCCI) is a low temperature combustion strategy that has been the focus of numerous experimental and computational studies in the past decade. Several excellent articles review research progress on HCCI and other advanced engine strategies including discussions of important limitations of current scientific understanding [2,5], demonstration of operating modes $[2,4,5]$, and advances (existing and required) in related engine technology $[2,4,5]$.

Methods of advanced combustion in IC engines often encompass mixed modes of combustion, in which flames and autoignition processes are simultaneously contributing to combustion and heat release rates. For example, during spark-assisted compression ignition (SACI), a spark plug is used to initiate a flame into the nominally homogeneous or partially stratified fuel/air charge in an internal combustion engine. SACI has been demonstrated to expand high and low load operation beyond HCCI boundaries $[6,7,8]$. However, methods to optimize SACI and other mixed modes of combustion are limited by the lack of fundamental understanding of flame propagation and autoignition interactions at conditions relevant to advanced engine strategies. Moreover, advanced combustion strategies like HCCI, SACI and gasoline direct injection (GDI) often consider highly dilute operation as a means to achieve high efficiency goals and meet emerging and more strict emissions requirements. These strategies typically target either (globally) fuel lean or stoichiometric conditions. The combination of 
high levels of dilution and fuel lean reactant mixtures is particularly challenging, as flame propagation and heat release rates decrease dramatically compared to undiluted stoichiometric conditions.

There is also a significant lack of fundamental combustion data, such as flame speeds and flammability limits at the state and reactant mixture conditions important to advanced combustion in IC engines. This gap complicates optimizing engine operation, especially the development and validation of theory and models which accurately describe mixed modes of combustion like SACI. Consequently, the objective of the current study is to experimentally characterize flame and autoignition interactions of iso-octane (an important reference fuel) and air mixtures at premixed, moderate temperature $(925-1000 \mathrm{~K})$ and pressure $(>7.5 \mathrm{~atm})$ conditions relevant to advanced engine strategies. The technical approach of this study leverages the well-defined mixture and state conditions that can be created using a rapid compression facility (RCF). Previous studies have demonstrated the value of RCFs as experimental platforms for providing important insights into the effects of mixture stratification on spark ignited flames during direct injection of the fuel $[9,10,11,12,13]$. Much has been learned from these previous RCF studies, including the effects of spark and fuel timing on mixture stratification and the resulting flame propagation [9-13]. The focus in the current work differs fundamentally from these previous studies as the focus is on flame/autoignition interactions at conditions with nominally homogeneous initial conditions, where thermal and mixture stratification have been minimized prior to spark igniting the mixture. Specifically, the effects of flame propagation on the autoignition delay time are determined in this study and the flammability limit for lean, dilute, premixed iso-octane air mixtures is determined. Measurements of flame propagation rates were also made for mixtures in which flames were successfully initiated and sustained in 
the test gas mixture.

\section{Experimental approach}

All experiments were conducted using the University of Michigan rapid compression facility (UM RCF) which has been used for numerous autoignition studies, including extensive characterization of iso-octane autoignition $[14,15,16,17]$. The UM RCF is essentially a chemical reactor that creates nominally uniform temperature and pressure conditions using a free piston to compress a test gas mixture. The test section of the UM RCF provides excellent optical and physical access to interrogate the gases during autoignition. The technical approach used in this study compared autoignition data with and without using a spark plug to initiate flames during the ignition delay time. The autoignition characteristics of the mixtures were determined using the pressure time history, and the characteristics of flame propagation were determined using high-speed imaging. The spark/autoignition experiments were also used to identify flammability limits as a function of dilution for fuel lean iso-octane air mixtures.

\subsection{Rapid compression facility details}

Details of the dimensions, operating procedure, and results of RCF characterization studies have been described previously and can be found in Donovan et al. [18] and He et al. [15]. The key features are highlighted here: The UM RCF consists of a driver section, driven section, test section, a sabot or free piston, a globe valve, and a mixing manifold. The driver section is separated from the driven section by a fast acting hydraulic globe valve assembly. Due to the high pressure differential across the globe valve assembly, a thin $(0.05 \mathrm{~mm}$ thick $)$ and scored plastic (Mylar) sheet is placed between the vacuum side of the valve assembly and the driven section to prevent air leaking into the evacuated driven section. The RCF achieves desired 
thermodynamic conditions through compression heating of the test-gas mixture by the sabot. The sabot consists of a solid plastic (Delrin) body with a brass counterweight located in the posterior and a detachable disposable nosecone made of deformable ultra-high molecular weight polyethylene. The sabot design includes two u-ring seals to minimize blow-by of the driver gases into the driven section during compression of the test-gas mixture.

As shown in Figure 1, downstream of the driven section is the test manifold, which consists of the converging, extension, and test sections. The converging section traps the cold boundary layer gases outside the test section to maximize test times at high temperatures and pressures, by minimizing fluid mixing and heat losses. The critical dimensions of the extension section are the internal diameter of $5.08 \mathrm{~cm}$ and the axial length of $8.05 \mathrm{~cm}$.

A new test section was fabricated from 316L stainless steel for this study to allow a spark plug to be mounted in the test section. The critical dimensions of the test section are the internal diameter of $5.08 \mathrm{~cm}$ and the axial length of $5.88 \mathrm{~cm}$. For each experiment, the sealed test volume consists of the test section volume and part of the extension section volume. The nosecone seals the test section by an annular interference fit in the extension section, resulting in a nominal test volume of $186.1 \mathrm{~cm}^{3}$. The test section is sealed using a polycarbonate endwall, $12.7 \mathrm{~mm}$ thick, and a load distribution plate that allows optical access for end-view imaging. Polycarbonate is more durable than quartz and polycarbonate provides comparable transmission efficiency to quartz in the visible spectrum, where the transmission efficiency of quartz is $\sim 90 \%$ and of polycarbonate is $85-90 \%$ in the wavelength range $390-700 \mathrm{~nm}$.

The pressure time histories for each experiment were measured using an amplified high-speed transient piezoelectric pressure transducer (Kistler 6045A transducer and Kistler 5010B charge amplifier). As shown in Figure 1, the pressure transducer was mounted on the 
bottom of the test section (i.e. at the piston or end view 6 o'clock position), and the spark plug was mounted at the 11 o'clock position. The orientation of the transducer and spark plug are not expected to effect the results of this study. The information is provided to orient the imaging data. All data except the camera imaging results were recorded using a 32 bit data acquisition system (National Instruments cDAQ-9172) operating at $100 \mathrm{kHz}$ and collected using a custom data acquisition program (LabView, 2011).

\subsection{Spark ignition system details}

The spark ignition system used in this study is similar to traditional electronic ignition systems used in automotive applications. The spark plug is a production flat seat iridium tip model (NGK IX BKR6EIX-11) set with a $1.1 \mathrm{~mm}$ gap between the central and ground electrodes. The central electrode sits $5 \mathrm{~mm}$ proud relative to the wall of the test section. An ignition module (Wells DR178) was used to signal an ignition coil (Accel 140024) with a maximum discharge voltage of 48,000 V. The ignition coil was powered by a regulated power supply capable of 12 A output (Pyramid PS-14KX 13.8 V) and connected to the spark plug using a spiral wound, silicone-sleeved, low resistance conducting spark plug wire. The amount of spark discharge energy was not changed throughout the experimental study. Thus, within the

tolerance expected for a typical production automotive ignition system, the spark discharge energy remained constant for every experiment. The minimum ignition energy for each mixture composition will vary to some degree. The results may therefore be sensitive, to some extent, to the amount of ignition energy introduced to the test-chamber.

The ignition module was triggered by the falling edge of a $2.5 \mathrm{~V}, 2 \mathrm{~ms}$ square wave produced by a digital delay/pulse generator (Stanford Research, Inc. DG535). The combined resistance 
of the secondary coil, insulated connecting wire, and the spark plug was measured to be 14.25 $\mathrm{k} \Omega$. The timing of the spark discharge was targeted to occur at the end of the first quartile of the predicted ignition delay time as determined by evaluating the Walton et al. [14] iso-octane correlation at the targeted experimental conditions. This methodology ensured the spark discharge occurred after the end of compression by the sabot and early during the autoignition delay time, to allow the maximum time for a potential flame to propagate.

\subsection{High-speed imaging system details}

A high-speed color digital video camera (Vision Research Phantom v711) was located downstream of the transparent end wall along the axis of the test section to record end-view imaging during the experiments. The high-speed camera featured a 1280 x 800 pixel CMOS sensor (Vision Research) with a 7 gigapixel/second throughput capable of recording from 7,530 frames per second (fps) at a maximum resolution of 1280 x 800 pixels to $680,000 \mathrm{fps}$ at a maximum resolution of $128 \times 8$ pixels. The CMOS sensor used a combination of four filters to achieve particular spectral response resulting in red, green, and blue output signals. The blue signal was acquired using a bandpass filter with peak transmittance at $455 \mathrm{~nm}$ and half-power transmittance at wavelengths of $406 \mathrm{~nm}$ and $508 \mathrm{~nm}$. The green signal was acquired using a bandpass filter with a peak transmittance at $540 \mathrm{~nm}$ and half-power transmittance at wavelengths of $478 \mathrm{~nm}$ and $596 \mathrm{~nm}$. The red signal was acquired using a bandpass filter with peak transmittance at $636 \mathrm{~nm}$ and half-power transmittance at wavelengths of $579 \mathrm{~nm}$ and $660 \mathrm{~nm}$. A low-pass filter with a cutoff frequency of approximately $715 \mathrm{~nm}$ was used to attenuate infrared emission. The camera lens assembly included a $50 \mathrm{~mm}$ high-speed lens (Navitar DO-5095 f/0.95), a $62 \mathrm{~mm}$ magnification lens (Hoya +4) to decrease the depth of field, and a $62 \mathrm{~mm}$ lens 
(Hoya Pro1 Digital Filter) to reduce internal light scattering and reflections in the lens assembly. The front lens element (Navitar DO5095) is made of single anti-reflective coating glass that can reflect up to $4-5 \%$ of incoming light. The digital filter (Hoya Pro1) is a multi-coated filter that features three layers of anti-reflective coating, thus reducing the reflected light to just $1-2 \%$ of incoming light. Internal light scatter, caused by stray reflected light, should be reduced because stray light can hit the CMOS sensor and create non-physical effects such as flares or ghosting. The camera was triggered using a digital delay/pulse generator (Stanford Research, Inc. DG535). The recording time was centered on the end of compression (i.e. the nosecone seating event) by applying a delay of $6.5 \mathrm{~ms}$ from when the digital delay/pulse generator was initially triggered by the sabot.

Camera software (Vision Research Phantom Software PCC 2.0.717.0) was used to set-up, calibrate, and capture all relevant videos. The camera was focused on the plane of the spark plug electrode prior to every experiment using a high exposure setting and corresponding low frame rate setting. A digital white-balance was performed as necessary using a white calibrating sheet of paper to ensure the red, green, and blue signals were balanced in magnitude. The exposure was decreased until the sensor did not detect any pixel saturation; at this point, the digital white balance was performed through the software. The camera settings were then adjusted to the appropriate resolution (512 x 512 pixels), frame rate (10,000 fps), and exposure $(99.64 \mu \mathrm{s})$ settings for the experiments. For the settings applied in this study, one pixel is equal to approximately $0.1 \times 0.1 \mathrm{~mm}$. The zero signal level for the CMOS array was calibrated with the lens cap on the camera using the current session reference function of the camera control software.

The high-speed videos were analyzed frame-by-frame using a combination of the camera 
specific software (Phantom SDK 12.0.705.0) and algorithms developed for this work and implemented in Matlab (R2012a). The image analysis was used to determine the location of the flame front in each image, for experiments where a flame was successfully initiated. For each experiment, a threshold was applied to convert the color images to binary scale, and an origin was defined as the centroid of the spark discharge. Vectors originating from the centroid were used to determine the location of the flame front in each frame. As will be shown later, the flames were often irregular in shape, and apparent flame propagation rates were determined along the measurement vectors from the time histories of the flame front location.

\subsection{Experimental procedure}

The test gas mixtures were made in a stirred mixing tank external to the RCF. A manifold was used to prepare the test gas mixtures using ultra high-purity components. The purity and source of the reactants are provided in the supplemental material. The partial pressures of the gases (0-100 torr and 0-1000 torr) were measured using two capacitance diaphragm pressure gauges, respectively (Varian CeramiCel VCMT12TFA and VCMT13TFA). The partial pressures were varied in different mixtures to achieve the targeted fuel-oxygen equivalence molar ratio, $\phi$, and inert gas to oxygen, $\mathrm{I}_{2} \mathrm{O}_{2}$, molar ratio. Each test gas mixture was stirred at 500 revolutions per minute (rpm) for a minimum of 20 minutes to ensure mixture homogeneity.

After the test gas mixture was prepared, each ignition experiment used the following process. The sabot was placed at the upstream end of the driven section. The driven section was evacuated and then filled with the test gas mixture to an initial pressure of $P_{o}=63.6-67.3 \pm 0.3$

torr. The hydraulic globe valve was actuated, launching the sabot down the length of the driven section until the nosecone of the sabot seated via an interference fit in the extension section. 
The RCF was disassembled, cleaned, and re-assembled between each experiment.

A laser diode $(50 \mathrm{~mW}, 532 \mathrm{~nm})$ paired with a photodetector (Hamamatsu S1787-12) were located slightly upstream of the test section (aligned orthogonal to the axis of the RCF) and used to determine the time the sabot passed the laser diode/photodetector location. When the sabot passed the measurement port (and blocked the laser beam), a signal was sent from the photodetector to trigger two digital delay/pulse generators (Stanford Research, Inc. DG535) that in turn triggered the spark and data acquisition systems. The effect of changing the spark timing on the lean flammability was investigated for some experiments. The time of the spark discharge was varied from the end of the first, second, and third quartiles of the predicted autoignition delay time. No effect of spark timing was observed on the lean flammability limit. For the majority of the experiments, the spark timing was set for the end of the first quartile of the predicted ignition delay time, in order to maximize the time for flame propagation and therefore maximize the effects of flame propagation on autoignition.

\section{Results}

\subsection{Flame effects on test gas conditions}

Experiments were conducted over a range of mixture compositions, targeted temperatures and pressures, and with and without the use of the spark plug to initiate flames. Figure 2 shows typical pressure time history and imaging results for an experiment in which the spark system was applied. The results are for a mixture with an inert gas to oxygen ratio of $I: O_{2}=4.99$ (mole basis) and a fuel to oxygen equivalence ratio of $\phi=0.99$ (mole basis). The pressure and

pressure derivative time histories are shown in the upper panel. Select frames from the imaging sequence are shown in the lower panel. The images in the figure are color enhanced for clarity, 
and not all frames in the video file are presented. The end of compression (EOC) pressure for the experiment is $P_{E O C}=8.4 \mathrm{~atm}$ and the EOC temperature is $T_{E O C}=976 \mathrm{~K}$, as determined by numerical integration of the isentropic compression relation Eq. (1)

$$
\int_{\mathrm{T}_{0}}^{\mathrm{T}_{\mathrm{EOC}}} \frac{\gamma}{\gamma-1} \mathrm{~d} \ln \mathrm{T}=\ln \left(\frac{\mathrm{P}_{\mathrm{EOC}}}{\mathrm{P}_{0}}\right)
$$

where $P_{o}$ is the initial charge pressure, $T_{o}$ is the initial charge temperature (typically $298 \mathrm{~K}$ ), and $\gamma$ is the temperature dependent ratio of the specific heats of the unreacted mixture, which is determined using the NASA Thermodynamic Data Base [19].

In Figure 2, EOC is set as time $t=0$, and volumetric autoignition of the mixture is indicated by the maximum rate of pressure rise after the EOC, $d P / d t_{\max }$. Volumetric autoignition also corresponds with the high intensity chemiluminescence that fills the imaging window in the last frame of the sequence presented in the lower panel of Figure 2. The autoignition delay time, $\tau_{i g n}$, is determined from the pressure and pressure derivative time histories as the elapsed time between the $P_{E O C}$ and maximum rate of pressure rise, $d P / d t_{\max }$, as shown in Figure 2.

The effects of the spark are evident in the pressure time history and the imaging sequence. The compression process prior to the EOC is smooth. Immediately following EOC, there is a slight observable decrease in the test section pressure caused by cooling of the test gases due to the colder test section walls. The decaying oscillatory behavior in the pressure signal, observed temporarily after the EOC, is an artifact of the fast Fourier transform filter used to reduce the noise recorded by the pressure transducer which originates from the impact of the nosecone seating. The spark trigger signal is included for reference in the upper panel of Figure 2 as the dotted line (arbitrary units). The falling edge of the spark trigger signal occurs at $t=3.63 \mathrm{~ms}$, and the spark plasma appears within approximately $110 \mu \mathrm{s}$ of the trigger signal in this experiment. A flame kernel is initiated by the spark discharge, and a flame propagates outward 
from the spark electrode. Within approximately $1 \mathrm{~ms}$ of the falling edge of the spark signal, the pressure in the test section starts to increase. The rate of pressure rise steadily increases prior to volumetric ignition, and as seen in the imaging data, the pressure rise correlates with the progress of the flame propagation through the test gas mixture. The increase in pressure prior to volumetric autoignition is primarily associated with compression heating of the remaining unburned mixture by the spark initiated flame. Pressure rise can also occur due to exothermic reactions during the autoignition delay time. As will be shown below, the chemical contribution can be small relative to the effects of compression heating; however, the relative contributions will be a function of the volume of the test section and the energy content of the mixture.

EOC conditions are appropriate initial conditions for each experiment and a summary of the EOC conditions is provided in Table 1. Additionally, in previous UM RCF autoignition studies $[14,20]$, time-integrated values for pressure and temperature were found to represent the test conditions quite well, in terms of correlating $\tau_{\text {ign }}$ data with the average state conditions experienced by the unburned mixture throughout the autoignition delay time period. In this study, the time integrated conditions are outcomes of the flame and autoignition interactions for a specific set of mixture composition, spark timing, and EOC conditions. As seen in Figure 2, using the EOC conditions to define the state conditions of the experiment would improperly estimate the pressure (and consequently the temperature) of the gases in the test section at the time of volumetric autoignition. For these experiments, the time-integrated values capture the effects of heat losses as well as the (potentially offsetting) effects of compression heating due to flame propagation. Thus, the effective state conditions reported in the current work are results of each flame/autoignition interaction experiment, and the effective conditions reflect the extent 
to which the EOC conditions have been affected by flame propagation and heat losses and flame propagation.

As in previous UM RCF studies $[14,20]$, the effective pressure, $P_{\text {eff, }}$, for each experiment is defined as the time-integrated average pressure from the maximum pressure due to compression $\left(P_{E O C}\right)$ to the time of maximum rate of pressure rise, $d P / d t_{\max }$, or

$$
P_{e f f}=\frac{1}{\left(t_{d P / d t \max }-t_{P_{E O C}}\right)} \int_{t_{P_{E O C}}}^{t_{d P / d t \max }} P \cdot d t
$$

The corresponding effective temperature, $T_{\text {eff }}$, for each experiment is determined using the same form as Eqn. (1), in which the end of compression parameters are replaced with the effective pressure and temperature:

$$
\int_{\mathrm{T}_{\mathrm{o}}}^{\mathrm{T}_{\text {eff }}} \frac{\gamma}{\gamma-1} \mathrm{~d} \ln \mathrm{T}=\ln \left(\frac{\mathrm{P}_{\text {eff }}}{\mathrm{P}_{\mathrm{o}}}\right)
$$

For reference, the effective conditions for the results presented in Figure 2 were $P_{\text {eff }}=8.8$ atm, and $T_{\text {eff }}=985 \mathrm{~K}$, and the EOC conditions were $P_{E O C}=8.4 \mathrm{~atm}$, and $T_{E O C}=976 \mathrm{~K}$.

The effects of flame propagation on pressure time history and resulting autoignition delay time are directly compared in Figures 3 and 4. Pressure and corresponding imaging data for a spark-initiated flame/autoignition experiment and a non-sparking autoignition experiment are presented in Figures 3 and 4, respectively. The end of compression conditions for the two experiments are virtually identical (spark-initiated experiment: $P_{E O C}=8.1$ atm, $T_{E O C}=942 \mathrm{~K}$; autoignition experiment: $P_{E O C}=8.2 \mathrm{~atm}, T_{E O C}=945 \mathrm{~K}$ ). As seen in Figure 3, the two pressure time-histories remain within $<1.5 \%$ until approximately $5 \mathrm{~ms}$ after the spark has been discharged or about $16 \mathrm{~ms}$ after the end of compression. The effects of compression heating by flame propagation lead to higher effective conditions for the spark-initiated experiment of $P_{\text {eff }}=8.2$ atm, and $T_{e f f}=945 \mathrm{~K}$, compared to the autoignition experiment conditions of $P_{e f f}=7.5 \mathrm{~atm}$, and 
$T_{\text {eff }}=926 \mathrm{~K}$. Note that the non-sparking experiment shows effects of chemical exothermicity during the ignition delay time. However, comparison of the two pressure time histories immediately prior to autoignition shows the contribution from compression heating to the increase in pressure is significantly higher than the contribution from chemical reaction for these particular experiments. The autoignition of the spark-initiated experiment is accelerated by $31 \%$ compared to the baseline autoignition delay time (spark-initiated experiment: $\tau_{i g n}=26.9$ ms; autoignition experiment: $\tau_{i g n}=39.0 \mathrm{~ms}$ ). The imaging data of Figure 4 show the uniform and rapid chemiluminescence associated with autoignition of the non-sparking autoignition experiments; note the compressed time scale of the images of the upper panel compared to the lower panel. For the upper panel, the peak illumination intensity corresponding to the autoignition event occurred between the fourth and fifth frames. The imaging data of the spark-initiated experiment show a complex and irregular flame surface is formed by the spark plasma, and the flame propagates outward from the spark plug electrode. Autoignition for the sparking experiments occurs in the volume of the unburned gases after the flame has propagated nearly halfway across the diameter of the test section.

Non-sparking experiments were conducted to ensure the new test section reproduced previous UM RCF measurements of autoignition delay times for iso-octane. A summary of these baseline autoignition experiments is provided in the supplementary material in Table A1 which includes the mixture composition, end of compression pressure and temperature, effective pressure and temperature, and autoignition delay time data. The results of the current work for baseline autoignition delay times agree well with previous UM RCF iso-octane autoignition data from Walton et al. [14] as seen in Figure A1 of the supplementary material. The cumulative experimental uncertainty of the autoignition delay time for the experiments in this study was 
$\pm 15 \%$.

The experiments in this work considered a broad range of compositions with equivalence ratios of $\phi=0.20$ to 0.99 and inert to oxygen dilution ratios of $I: O_{2}=3.76$ to 7.47 (mole basis); however, the pressures and temperatures intentionally spanned a narrow range to facilitate the determination of lean flammability limits and to minimize the effects of state conditions on flame propagation. Consequently, the end of compression pressures spanned $P_{E O C}=8$ to 8.5 atm, and the end of compression temperatures spanned the range $T_{E O C}=942-1000 \mathrm{~K}$. Table 1 provides a summary of the results of the experiments in which the spark discharge system was applied. The results include the mixture composition, state conditions, autoignition delay time data and information on whether a flame was successfully initiated for each experiment. The experiments in which flames were not successfully initiated are identified as below the flammability limit (BFL) in Table 1 and were used to identify the lean flammability limits for the mixtures.

In the current work, and with RCM studies in general, buffer gas composition was varied to control the end-of-compression temperature and pressure of the experiments. While the composition of the buffer gases can affect autoignition delay times in the negative-temperature-coefficient region via chemical interactions and through the heat capacity of the mixture [21], the chemical effects are expected to be negligible $(<5 \%)$ at the conditions studied here, which are outside the NTC region. Additionally, the heat capacity of each reactant mixture was calculated using the mixture composition and the end of compression temperature. The average mixture heat capacity for all mixtures was $26.93 \mathrm{~J} / \mathrm{mol}-\mathrm{K}$ with a standard deviation of $1.37 \%$. Consequently, thermal effects due to compression heating (and endothermic and exothermic chemical reactions) are expected to be comparable for all 
experiments.

For some experiments, the effects of spark timing were considered and compared with baseline experiments with identical end of compression conditions and mixture compositions, but where the spark system was not used. All these experiments were conducted at conditions above the flammability limit, and flames were successfully initiated and sustained in each of these sparking experiments. The pressure time histories for these data are provided in the Appendix. Experiments where the spark was triggered in the second (Q2) and third (Q3) quartile showed negligible impact on the autoignition delay time (within the experimental uncertainty). Significant effect on the autoignition delay time was only observed when the flame was initiated early (during the first quartile), e.g. the results presented in Figure 3; however, not all Q1 sparking experiments affected the autoignition delay time. Figure 5 presents the change in the measured autoignition delay time relative to each corresponding baseline non-sparking measurement for the four end-of-compression temperatures considered in these experiments. When a decrease in autoignition delay time was observed, the pressure time history also showed a pressure rise above the baseline prior to the rapid pressure rise of autoignition, as seen in Figure 3. As discussed earlier, this pressure rise is attributed to compression heating of the unburned mixture by the flame, and results in an increase in the effective or time-averaged temperature of the experiment. Therefore the change in $T_{\text {eff }}$ relative to the baseline non-sparking experiment is also a metric of the impact of flame propagation on autoignition and is provided in Figure 5. The data show $\sim 2-31 \%$ decrease in the ignition delay time due to flame propagation with corresponding changes in average temperatures of $\sim 1-19 \mathrm{~K}$. The magnitude of compression heating is a function of the test gas mixture composition, spark timing, state conditions, and volume of the test chamber. While the data in Figure 5 are 
presented as a function of $T_{E O C}$, the energy content of the mixture may be a more appropriate parameter, as is discussed further below.

\subsection{Lean flammability limits}

The lean flammability limits defined by the fuel-to-oxygen equivalence ratio were determined at three levels of dilution for nominal end of compression conditions of $P_{E O C}=8.6 \pm$ 0.9 atm and $T_{E O C}=977 \pm 35 \mathrm{~K}$. For each dilution level, spark initiated experiments were conducted over a range of equivalence ratios from $\phi=0.20-0.99$. For each experiment, the spark was triggered and the imaging data were used to determine if a flame was successfully initiated and sustained. The effects of flame propagation were also observable in the pressure time history as a pressure rise prior to autoignition, as seen in Figures 2 and 3. For experiments in which flames were not successfully initiated by the spark discharge, no additional pressure rise was observed in the pressure time histories prior to autoignition.

The results of the flammability limit study are presented in Figure 6 as a function of mixture dilution. Conditions in which flames were successfully initiated and sustained in the chamber are presented as circles, while conditions in which a flame was not successfully initiated or the flame quenched before autoignition are presented as squares. The flammability limit is defined as the midpoint between the conditions in which flames were observed and conditions in which they were not. Multiple experiments were performed near the lean limit to ensure repeatability and using higher exposure settings of the camera, to maximize detection of the chemiluminescence from the flames. Furthermore, the image analysis code was applied to verify the classification of the experiments performed near the flammability limit, as the chemiluminescence could be relatively weak at those conditions. The results show the lean 
flammability limit for $\phi$ increased significantly, by $86 \%$, from air levels of dilution $\left(\mathrm{I}: \mathrm{O}_{2}=3.76\right)$ to the most dilute condition of $I: O_{2}=7.47$.

\subsection{Imaging results of flame propagation rates}

For experiments in which flames were successfully initiated by spark discharge and sustained, the imaging data were used to determine the propagation rate of the flames. Not all the imaging data could be analyzed to determine propagation rates, as some images had high uncertainty in the flame position due to overlapping flame fronts or weak chemiluminescence. However, for imaging data where the flame front was well defined, the location of the flame front along selected trajectories was determined as a function of time relative to an origin that was set as the centroid of the spark discharge. The position of the flame front was determined along trajectories at $0.0^{\circ}$ (horizontal), 26.6 $6^{\circ}, 45.0^{\circ}$ (diagonal), 63.4 , and $90.0^{\circ}$ (vertical) orientations as shown in the inset in Figure 7. For reference, the experimental results presented in Figure 7 are from the experimental results presented in Figure $2\left(\phi=0.99\right.$, inert to $\mathrm{O}_{2}$ ratio $=$ 4.99, $P_{E O C}=8.4 \mathrm{~atm}, P_{e f f}=8.8 \mathrm{~atm}, T_{E O C}=976 \mathrm{~K}$, and $\left.T_{e f f}=985 \mathrm{~K}\right)$. Results for the position of the flame along the measurement trajectories are presented in Figure 7, where time $t=0$ is now defined as the first time the spark plasma was observed. The time histories of the flame positions were smoothed using a two-point moving average filter. At early times, the position of the flame front was convolved with the spark plasma. After the flame was successfully initiated, the position data show the flame grew at similar rates of expansion along the different measurement trajectories for these experimental conditions, i.e. the flame development was generally uniform. The rapid increase in the position of the reaction front at $t \approx 5.5 \mathrm{~ms}$ was the result of volumetric autoignition. 
The propagation rates of the flame front(s) along the trajectories were determined by differentiating the smoothed flame position data with respect to time. The results based on the data of Figure 7 are presented in Figure 8. The average rate of propagation of the five trajectories is provided in Table 1 for each experiment where flame location was well identified. The propagation rate data were not corrected for stretch, density changes, or the effects of the proximity of and ignition energy of the spark discharge, and the results are not flame speed measurements. The propagation rate data describe the apparent or observed expansion rate of the flame surface. Laminar flame speed measurements cannot be accurately determined from these experiments for a variety of reasons. Flame stretch correction theory typically assumes spherical flames [22] and the flame surfaces observed in this study were irregular in many cases (see Figure 4). In addition, there was significant pressure rise during the time of flame propagation in the current experiments, which was beyond even the most generous corrections for stretch in a confined vessel with weak pressure rise [23]. Down-selecting the data within each experiment to meet the weak pressure rise criterion does not allow for enough usable time history to determine meaningful flame speed data. As seen in Figure 8, the deceleration of the flame front as pressure in the test section increased was significant, with speeds decreasing by over $30 \%$ from the maximum rates of $\sim 6 \mathrm{~m} / \mathrm{s}$ to less than $4 \mathrm{~m} / \mathrm{s}$ immediately prior to autoignition for this experiment. The variability in the flame speed data at early times is due to convolution of the flame initiation with the spark plasma. A minimum flame radius of $6 \mathrm{~mm}$ is recommended for flame speed measurements in order to ignore the effects of the ignition source [24], which would lead to even greater down-selection of the data from these experiments. Further complicating the assignment of a laminar flame speed determination is that the flames were propagating into a mixture which was reacting, and consequently the unburned mixture 
composition was changing as a function of time. For reference, calculated density ratios of the burned to unburned gases are provided in Table 1, but the propagation rates reported in the figures were not corrected for density.

Figure 9 presents another set of flame position data corresponding to the spark-initiated experiment results presented in Figure 3 and 4. For reference, the experimental conditions for the results presented in Figure 9 were $\phi=0.70$, inert to $\mathrm{O}_{2}$ ratio $=4.99, P_{E O C}=8.1 \mathrm{~atm}, P_{\text {eff }}=8.2$ atm, $T_{E O C}=942 \mathrm{~K}$, and $T_{\text {eff }}=945 \mathrm{~K}$. As in Figure $7, t=0.0 \mathrm{~ms}$ corresponds to the first observation of the spark plasma, and the origin for the measurements was the center of the spark plasma. Measurements were made along the five trajectories shown in Figure 7. Unlike in the data of Figure 7, the expansion of the flame fronts along the measurement trajectories in this experiment was not uniform spatially or temporally. As seen in the flame imaging (Figure 4), the flame surface created by the spark plasma in this experiment was more irregular in shape with multiple overlapping surfaces. As the flame surfaces interact and merge over time, abrupt changes in the flame surface along the measurement trajectories are recorded, as seen in Figure 9, and for this experiment, the flame development was not spatially or temporally uniform.

The propagation rates derived from the flame position data of Figure 9 are presented in Figure 10. The apparent flame speeds were significantly slower $(\sim 2-3 \mathrm{~m} / \mathrm{s})$ when compared to the equivalent dilution condition of Figure 8 , in which propagation rates of $\sim 4-6 \mathrm{~m} / \mathrm{s}$ are observed. Deceleration of the flame surface as pressure increased in the test section is evident in the data, although not to the same extent as observed for the higher equivalence ratio example presented in Figure 8. The two experiments had similar effective pressures $\left(P_{\text {eff }}=8.8\right.$ and 8.2 atm) with slightly higher effective temperature for the data of Figure $8\left(T_{\text {eff }}=985 \mathrm{~K}\right)$ compared to Figure $10\left(T_{\text {eff }}=945 \mathrm{~K}\right)$. The lower propagation rates of Figure 10 are attributed to the 
slightly lower temperature and the lower equivalence ratio of $\phi=0.7$ compared to $\phi=0.99$.

Average propagation rates were determined for each of the experiments in which the spark plasma successfully initiated a flame. The results were evaluated to determine if a correlation could be identified between the flame propagation rates and the ignition experimental conditions, including the reactant composition. The propagation rates were expected to be a function of the end of compression temperature and pressure, equivalence ratio, and dilution based on laminar flame theory. The cumulative effects of these parameters were determined by calculating the theoretical adiabatic flame temperature for each experimental condition using the thermochemistry for iso-octane and other reactants from the iso-octane mechanism (version 3) of Mehl et al. [25]. The initial reactant composition, temperature, and pressure were specified from each experimental condition. The computed results included the effects of dissociation on the adiabatic flame temperature. The results for the average flame propagation rates and the individual rates along each measurement vector are presented in Figure 11 as a function of the theoretical adiabatic flame temperature. Also included in the data are the conditions in which the spark plasma did not successfully initiate a flame.

The data show a strong correlation between the observed propagation rates and the energy content of the mixture as represented by the adiabatic flame temperature. Conditions with low energy content could not sustain flames and increasing the mixture strength, increased the propagation rate of the flames. Based on these results, the effects of flame propagation on autoignition can be anticipated to be more significant for mixtures with higher energy content, and the data of Figure 11 support that there may be an energy threshold, e.g. $\mathrm{T}_{\mathrm{ad}}>2000 \mathrm{~K}$, for the conditions studied here. It would be valuable to develop a quantitative and predictive measure of the impact of flame propagation on autoignition delay time. The data presented in 
the current work provide a valuable basis for developing such metrics; however, a larger range of pressures and temperatures must be considered for a more complete understanding of the range of effects that can be observed during flame/autoignition interactions.

\section{Conclusions}

The current work presents new data on the initiation and propagation of flames into premixed fuel/air mixtures at well-defined initial state conditions. The results of the study showed the effects of flame propagation were maximized when the flame was initiated early during the autoignition delay period (e.g. during the first quartile). Later ignition timing (e.g. during the second or third quartile of the autoignition delay period) reduced the impact of flame propagation even when flames were successfully initiated and sustained. When the effects of flame propagation were apparent on autoignition delay time, the impact was to accelerate ignition by approximately 2-31\%. Image analysis allowed apparent propagation rates of the flames to be determined. The high-speed imaging data also allowed flammability limits to be identified at conditions directly relevant to advanced engine strategies. Dilution had significant effect on the lean flammability limits, increasing from a lean limit of $\phi=0.35$ at air levels of dilution to $\phi=$ 0.65 at inert: $\mathrm{O}_{2}$ dilution of 7.5. The flammability limit was also well correlated with the theoretical adiabatic flame temperature. These results provide unique, vital, and quantitative new information for development and validation of theory and models of flame/autoignition interaction, as well as providing fundamental understanding of the physical and chemical interactions important to multi-mode combustion strategies like spark-assisted compression ignition. While the data encompass a relatively narrow range of pressures and temperatures, the

results provide several quantitative benchmarks of the impact of flame propagation on 
auto-ignition at well-controlled mixture and initial state conditions. Consequently, the data can be the basis for model validation as well as the development of broader fundamental combustion criteria to quantify the conditions where spark initiated flame propagation can impact auto-ignition both adversely (e.g. as in the case of end knock) and productively (e.g. SACI).

\section{Acknowledgements}

The authors acknowledge the generous support of the U.S. Department of Energy via the University of Michigan Consortium on Efficient and Clean High-Pressure, Lean Burn (HPLB) Engines. 


\section{List of Tables}

Table 1. Summary of experimental conditions and results for autoignition/flame interaction experiments. The mixture composition is provided on a mole basis. The equivalence ratio is based on iso-octane to $\mathrm{O}_{2}$ molar ratios. Experiments in which flames were successfully initiated by the spark discharge include the average propagation rate of the flames, $U_{\text {avg }}$. Experiments in which flames are not successfully initiated by the spark are denoted as below the flammability limit, BFL. Experiments in which flames are successfully initiated but apparent flame speed measurements were not performed are denoted as above the flammability limit, AFL. 


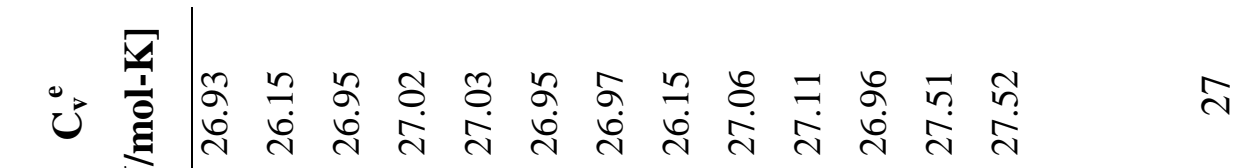

旅

U

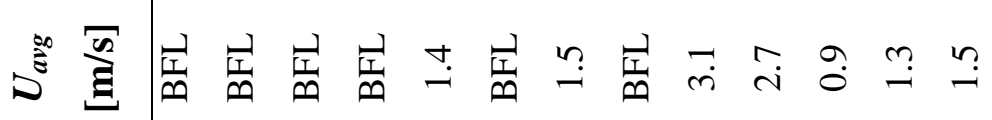

竎

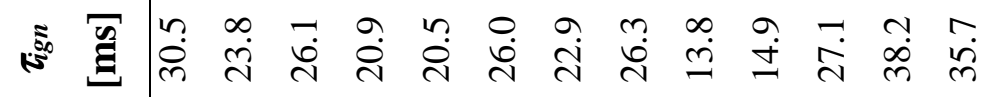

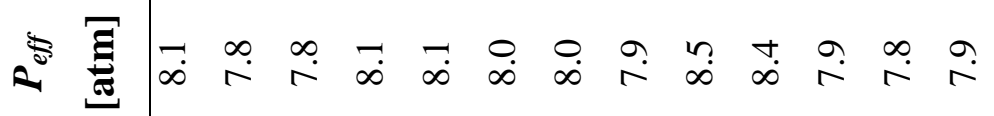

*

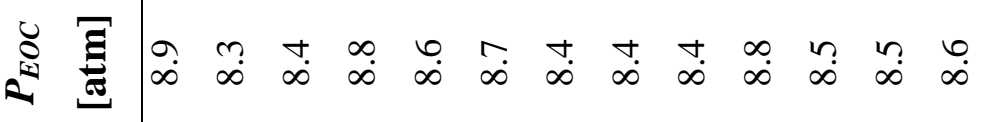

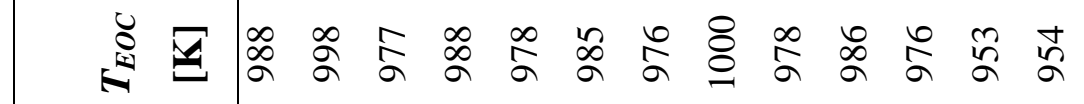

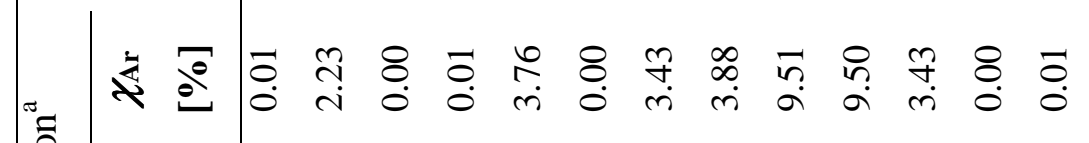
¿

:

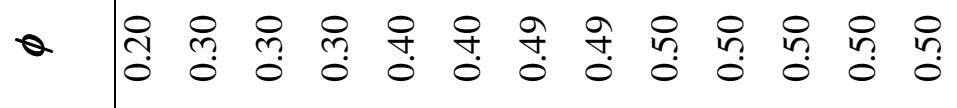




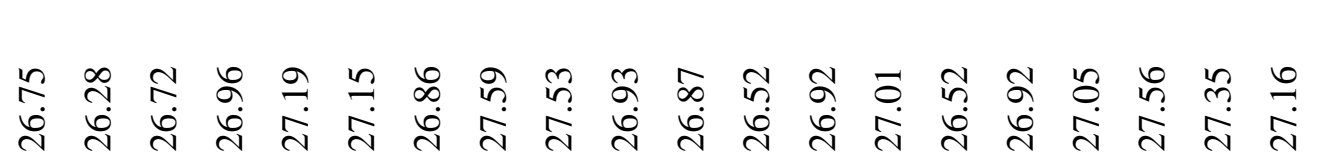

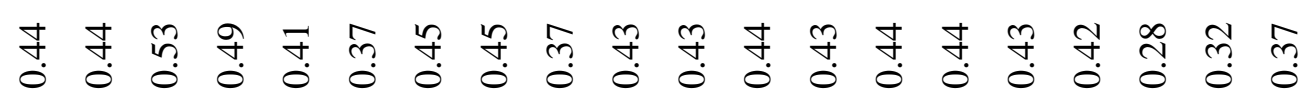

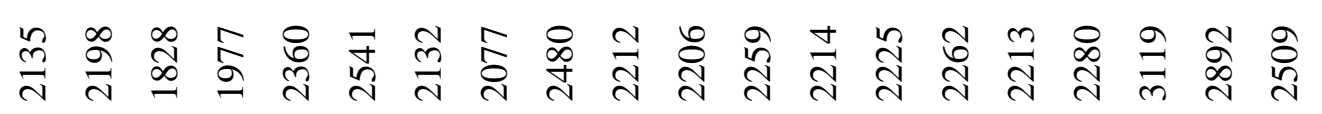

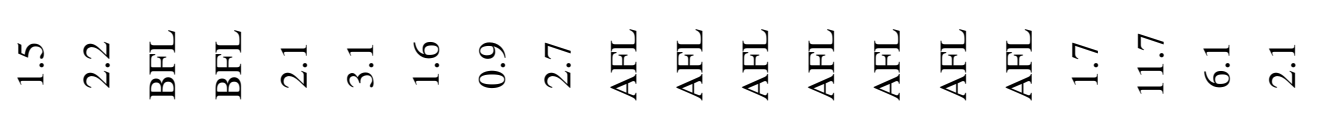

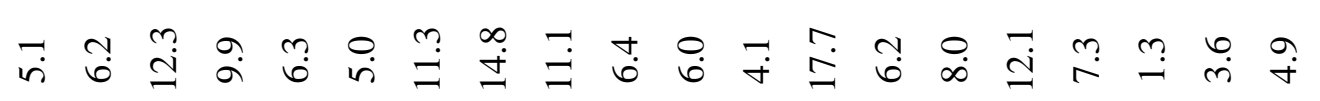

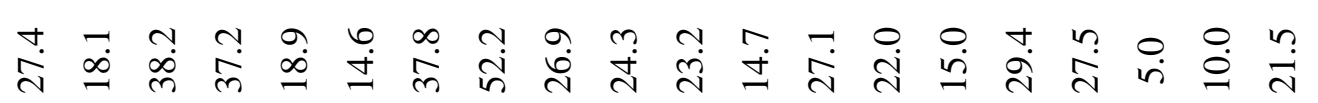

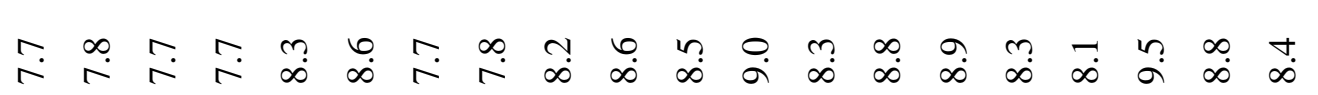

范

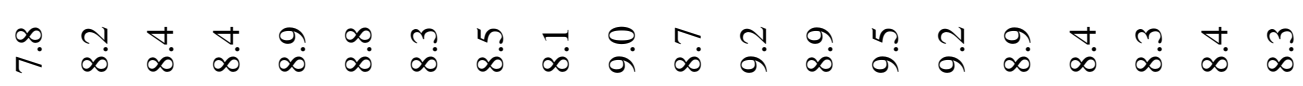

ลૂ。

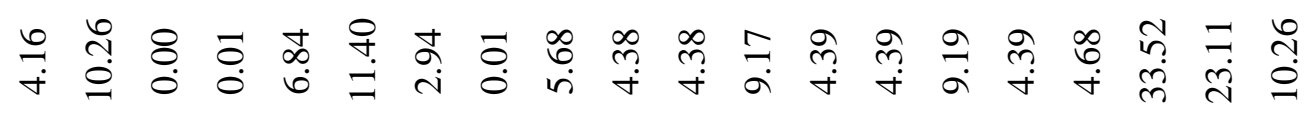

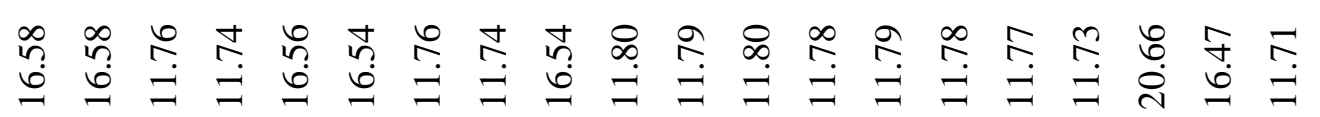

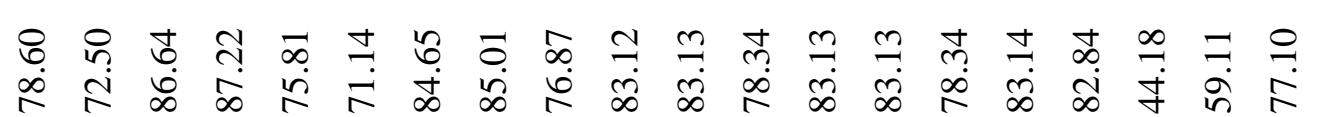

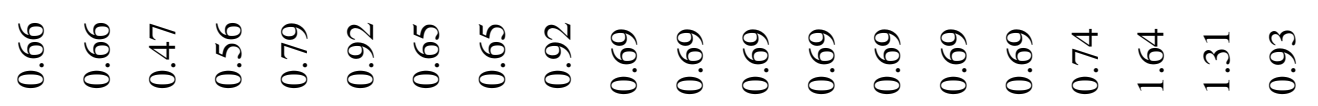

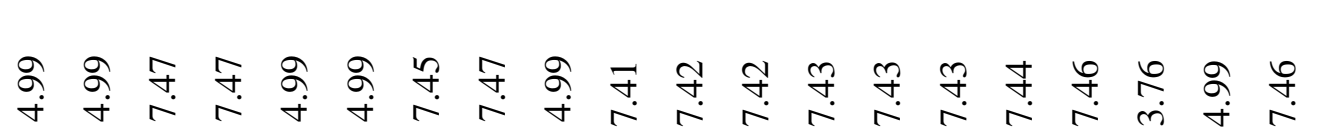

ஜ 


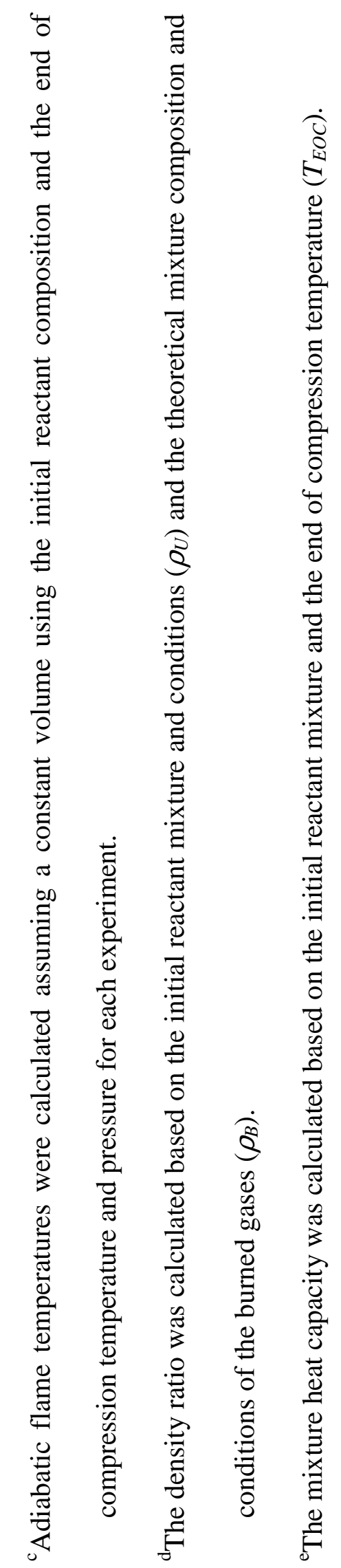




\section{List of Figures}

Figure 1. Schematics of the UM RCF showing the driven section, the test manifold, and the high-speed camera. The sabot location corresponds to the end of compression in the test section.

Figure 2. The top panel presents the pressure and pressure derivative time histories for a typical iso-octane autoignition/flame interaction experiment $\left(\mathrm{I}: \mathrm{O}_{2}=4.99, \phi=0.99, T_{E O C}=976 \mathrm{~K}\right.$, and $\left.P_{E O C}=8.4 \mathrm{~atm}\right)$. The lower panel presents selected frames from the video sequence. The spark triggering signal (arbitrary units) is included for reference as the dotted line.

Figure 3. Comparison of the effects of spark ignition on the pressure and pressure derivative time histories for iso-octane/ $\mathrm{O}_{2}$ mixtures with the same mixture composition and virtually identical end of compression conditions (spark experiment: $T_{E O C}=942 \mathrm{~K}$, and $P_{E O C}=8.1$ atm, no-spark experiment: $\left.T_{E O C}=945 \mathrm{~K}, P_{E O C}=8.2 \mathrm{~atm}\right)$.

Figure 4. High-speed imaging data (selected frames) corresponding to the two ignition experiments presented in Figure 3. The upper panel presents frames from the non-sparking experiment and the lower panel presents frames from the sparking experiment. Time $\tau=0$ corresponds to the end of compression for both image sequences. 
Figure 5. The effects of flame propagation on the measured ignition delay time and effective temperature relative to identical baseline autoignition experiments. The error bars represent the uncertainty in measurements of $\tau_{\text {ign. }}$

Figure 6. Summary of the experimental results for lean flammability limits as a function of dilution.

Figure 7. Time histories of the flame position as determined from the high-speed imaging data of the experimental results of Figure $2\left(\phi=0.99\right.$, inert to $\mathrm{O}_{2}$ ratio $=4.99, T_{E O C}=976 \mathrm{~K}$, and $P_{E O C}=$ $8.4 \mathrm{~atm})$. The pressure time history and spark plug trigger signals are provided for reference. Time $\mathrm{t}=0 \mathrm{~ms}$ corresponds to the first observation of the spark plasma. Measurements were made along five vectors with a common origin (set as the center of the spark plasma) as shown in the inset.

Figure 8. Results for apparent flame speed calculated using the derivative of the corresponding radial position data presented in Figure 7. Time $t=0.0 \mathrm{~ms}$ corresponds to the first observation of the spark plasma. The measurements are for the five trajectories presented in Figure 7.

Figure 9. Time history of the flame position as determined from the high-speed imaging data of the experimental results of Figure $3\left(\phi=0.7\right.$, inert to $\mathrm{O}_{2}$ ratio $=4.99, T_{E O C}=942 \mathrm{~K}$, and $P_{E O C}=$ $8.1 \mathrm{~atm})$. The corresponding pressure time history and spark trigger signal are shown for reference. 
Figure 10. Results for apparent flame speed calculated using the derivative of the corresponding radial position data presented in Figure 9.

Figure 11. Experimental measurements of the average flame propagation rates as a function of the theoretical adiabatic flame temperature. The open symbols are the average propagation rates along each of the measurement vectors shown in the inset of Figure 7. The solid symbols are the overall averages for each experiment. 


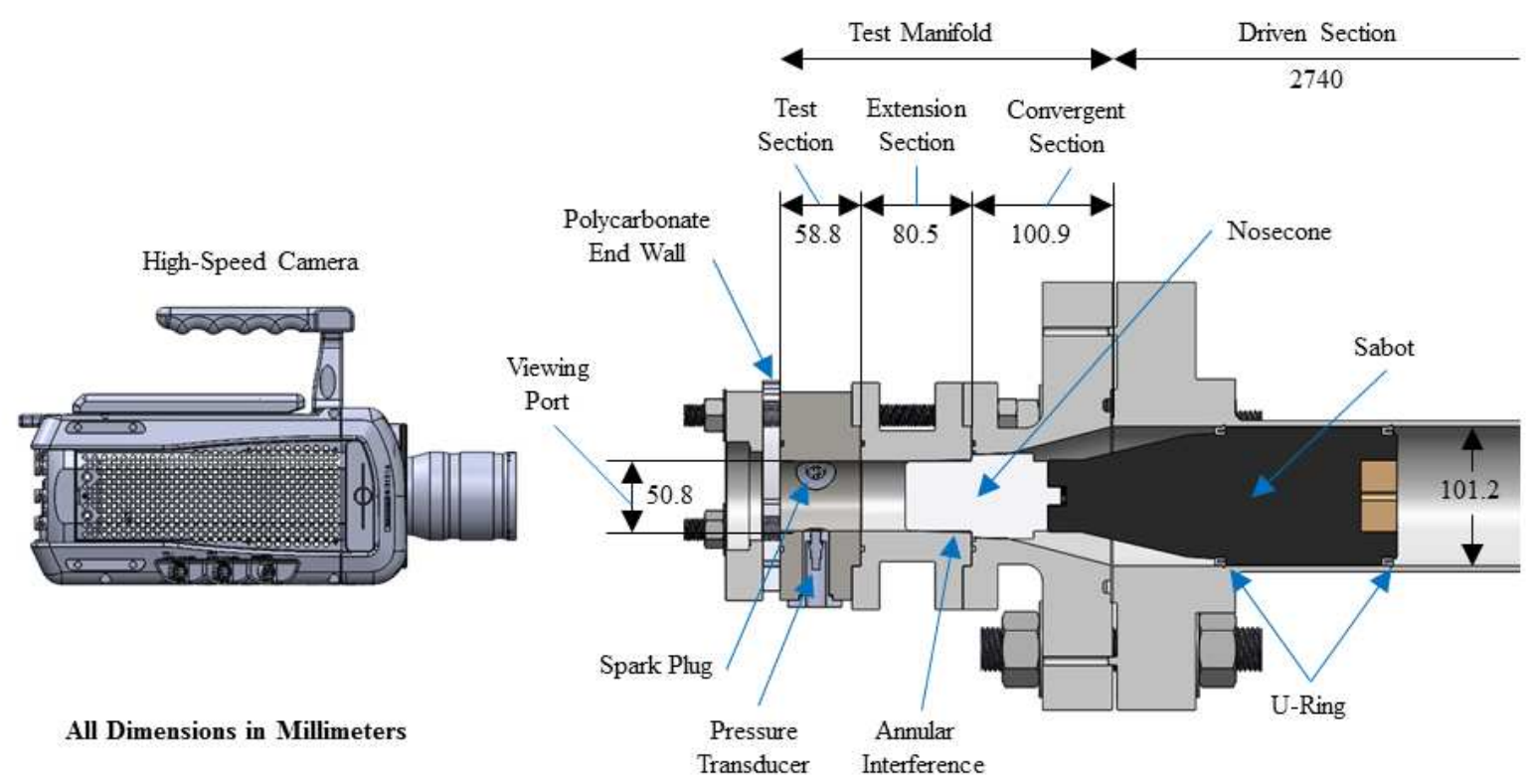

(a) Side-view cross-section

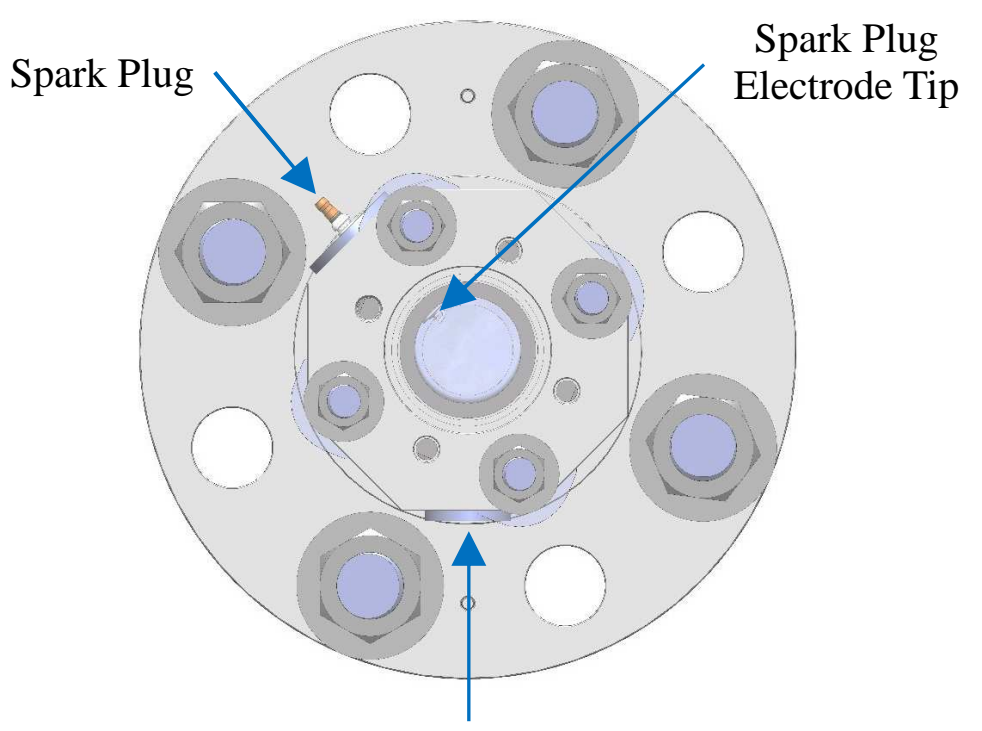

Pressure

Transducer

(b) End-view from camera perspective

Figure 1. Schematics of the UM RCF showing the driven section, the test manifold, and the high-speed camera. The sabot location corresponds to the end of compression in the test section. 


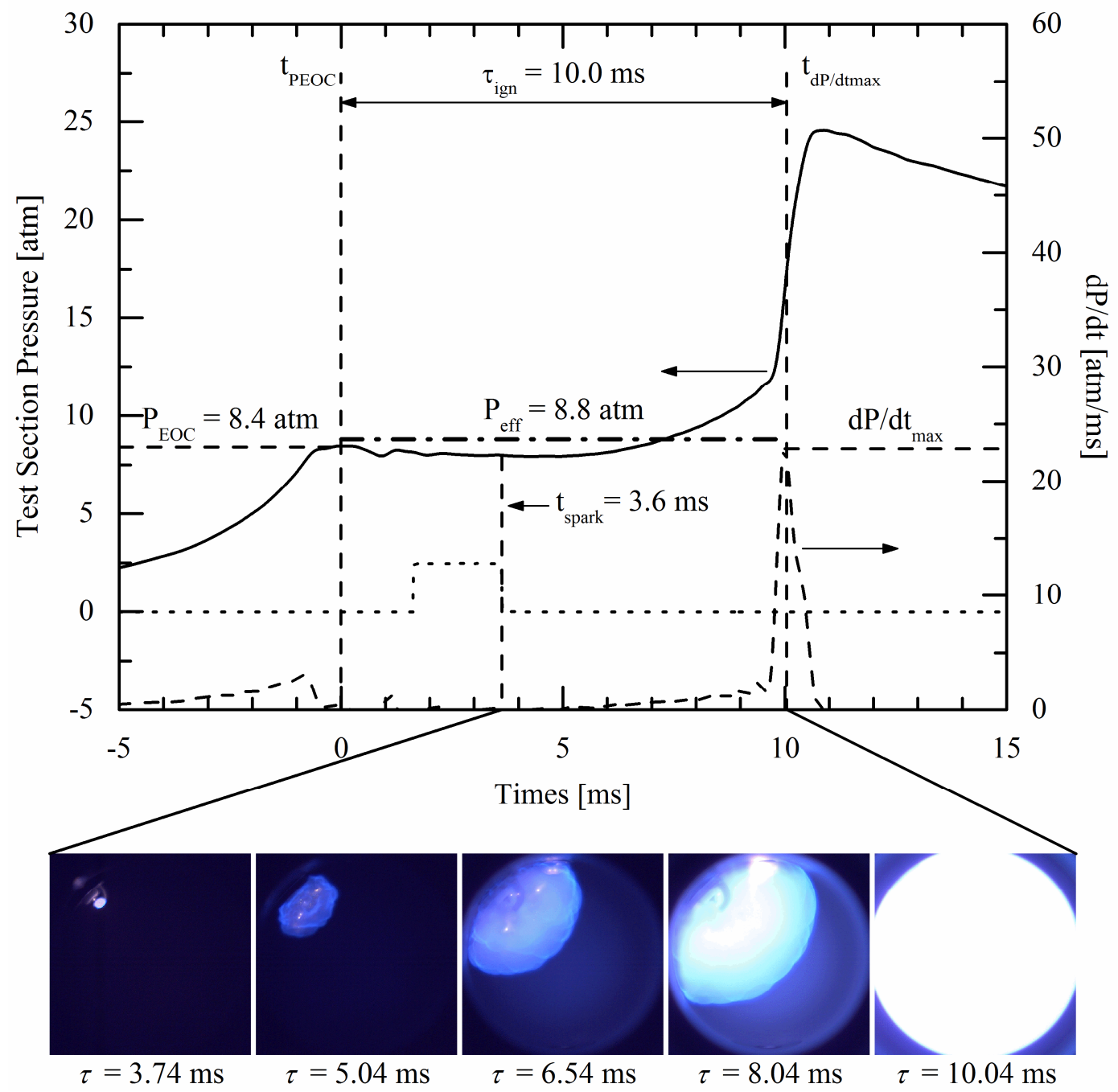

Figure 2. The top panel presents the pressure and pressure derivative time histories for a typical iso-octane autoignition/flame interaction experiment $\left(\mathrm{I}: \mathrm{O}_{2}=4.99, \phi=0.99, T_{E O C}=976 \mathrm{~K}\right.$, and $\left.P_{E O C}=8.4 \mathrm{~atm}\right) . \quad$ The lower panel presents selected frames from the video sequence. The spark triggering signal (arbitrary units) is included for reference as the dotted line. 


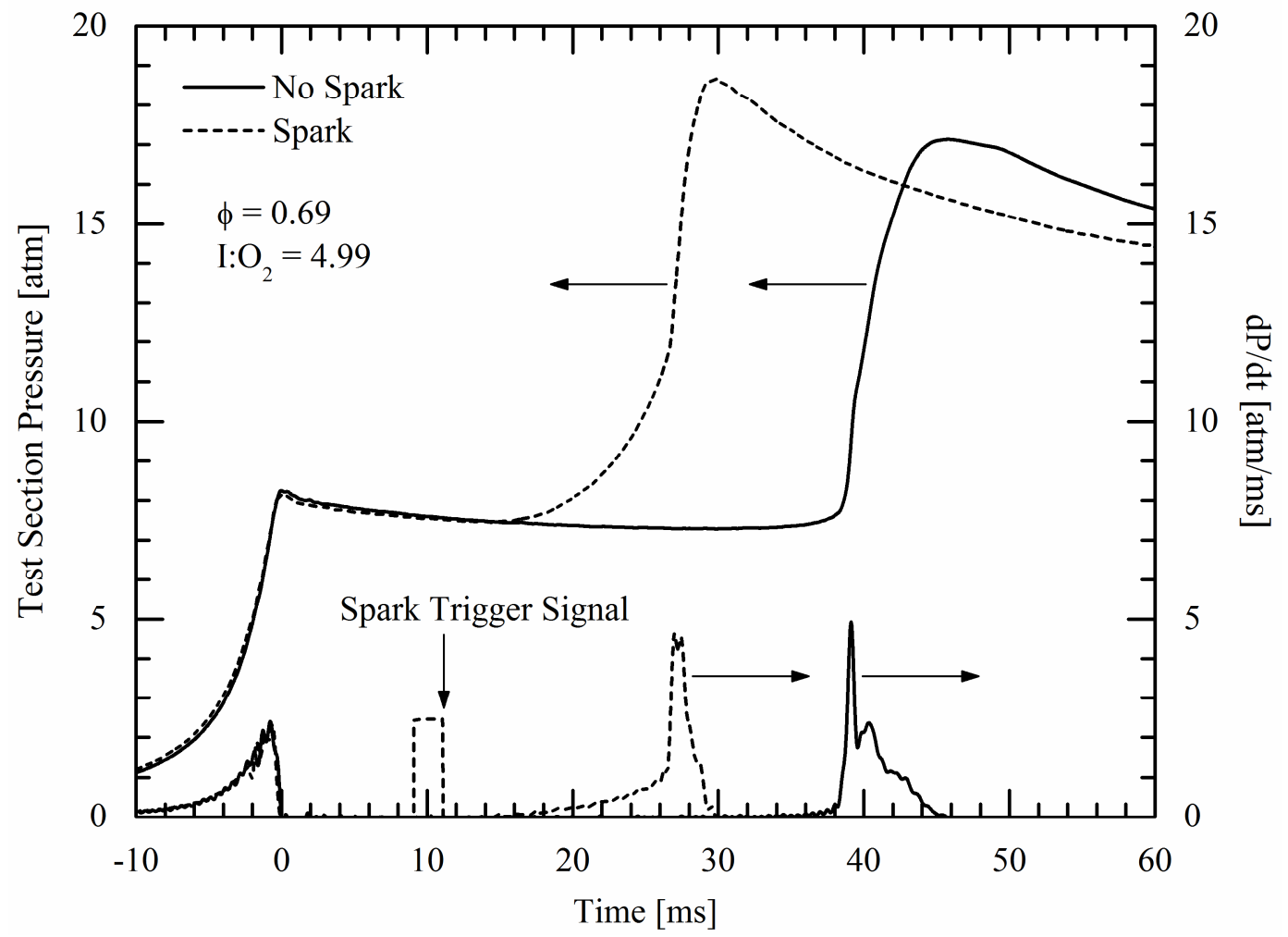

Figure 3. Comparison of the effects of spark ignition on the pressure and pressure derivative time histories for iso-octane/ $\mathrm{O}_{2}$ mixtures with the same mixture composition and virtually identical end of compression conditions (spark experiment: $T_{E O C}=942 \mathrm{~K}$, and $P_{E O C}=8.1 \mathrm{~atm}$, no-spark experiment: $\left.T_{E O C}=945 \mathrm{~K}, P_{E O C}=8.2 \mathrm{~atm}\right)$. 


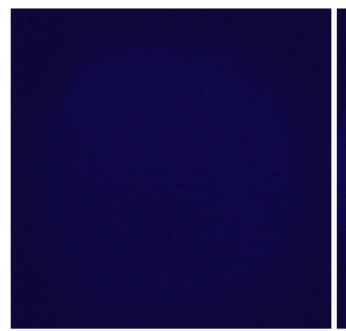

$\tau=38.33 \mathrm{~ms}$

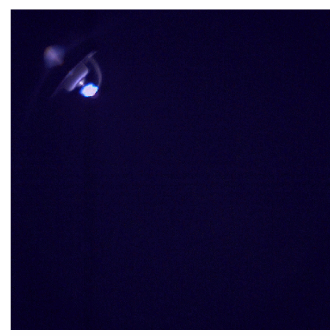

$\tau=11.19 \mathrm{~ms}$

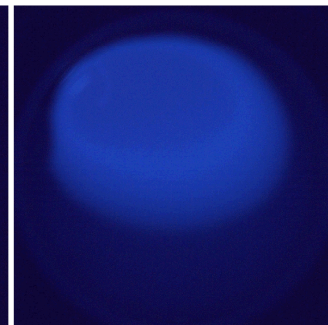

$\tau=38.53 \mathrm{~ms}$

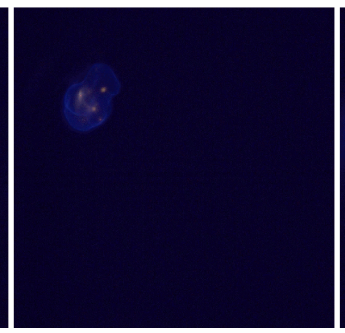

$\tau=13.69 \mathrm{~ms}$

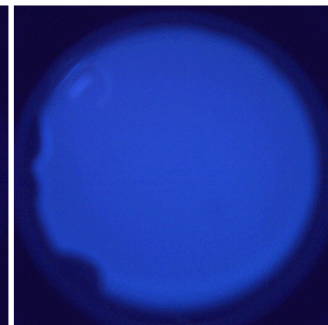

$\tau=38.73 \mathrm{~ms}$

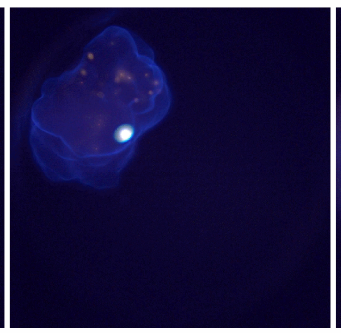

$\tau=16.89 \mathrm{~ms}$

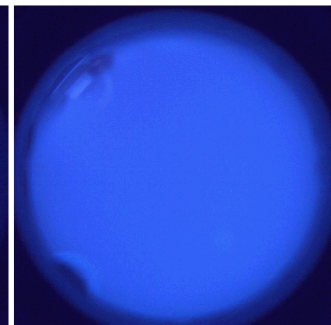

$\tau=38.93 \mathrm{~ms}$

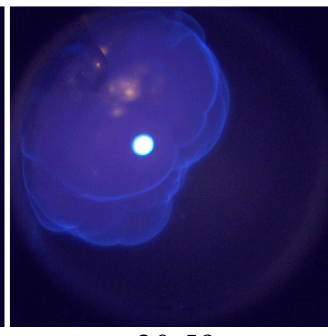

$\tau=20.59 \mathrm{~ms}$

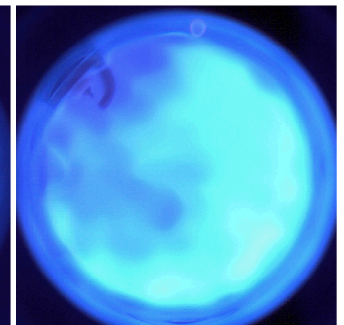

$\tau=39.13 \mathrm{~ms}$

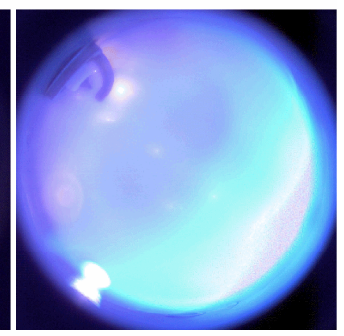

$\tau=26.99 \mathrm{~ms}$

Figure 4. High-speed imaging data (selected frames) corresponding to the two ignition experiments presented in Figure 3. The upper panel presents frames from the non-sparking experiment and the lower panel presents frames from the sparking experiment. Time $\tau=0$ corresponds to the end of compression for both image sequences. 


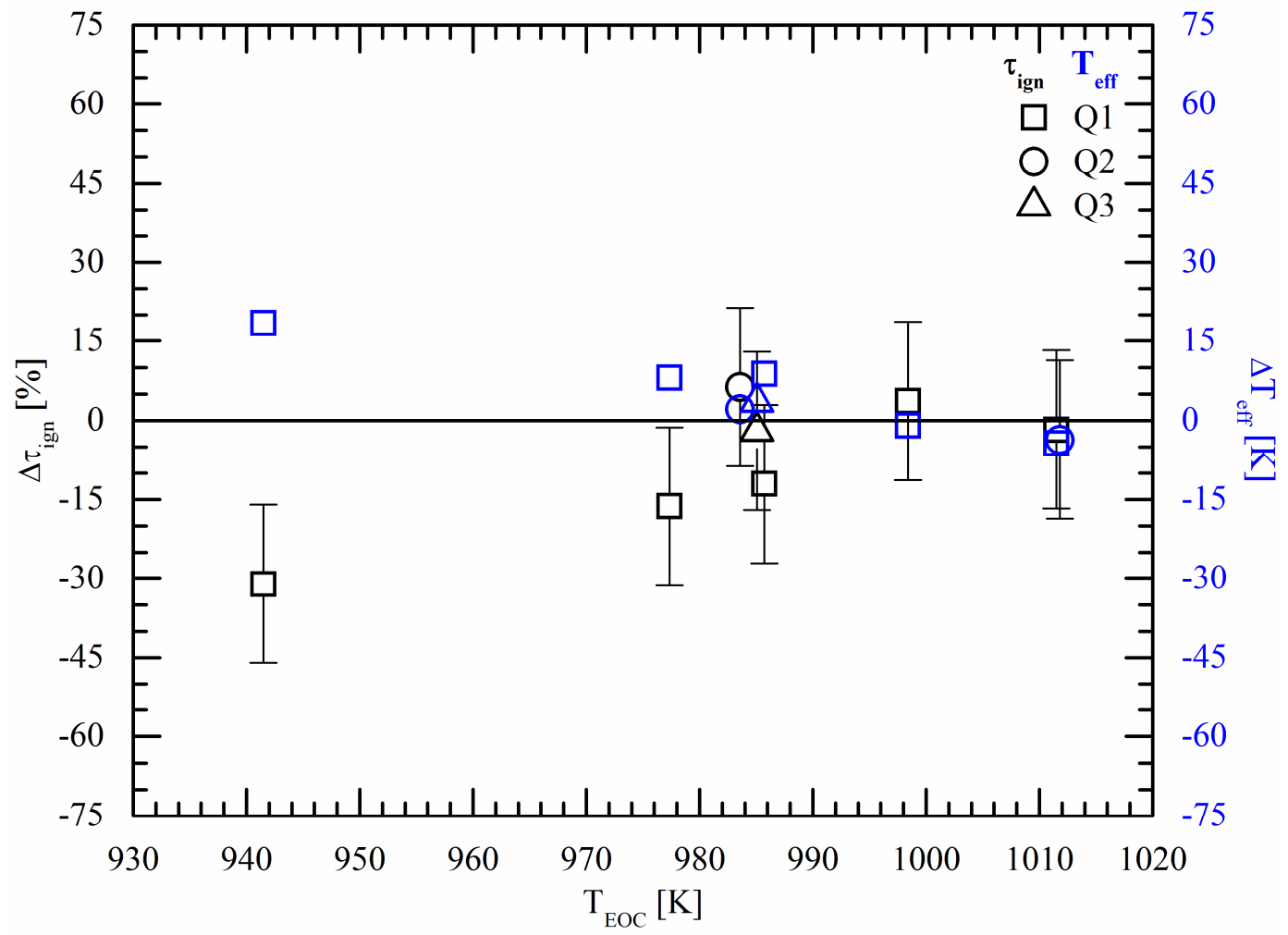

Figure 5. The effects of flame propagation on the measured ignition delay time and effective temperature relative to identical baseline autoignition experiments. The error bars represent the uncertainty in measurements of $\tau_{\text {ign. }}$ 


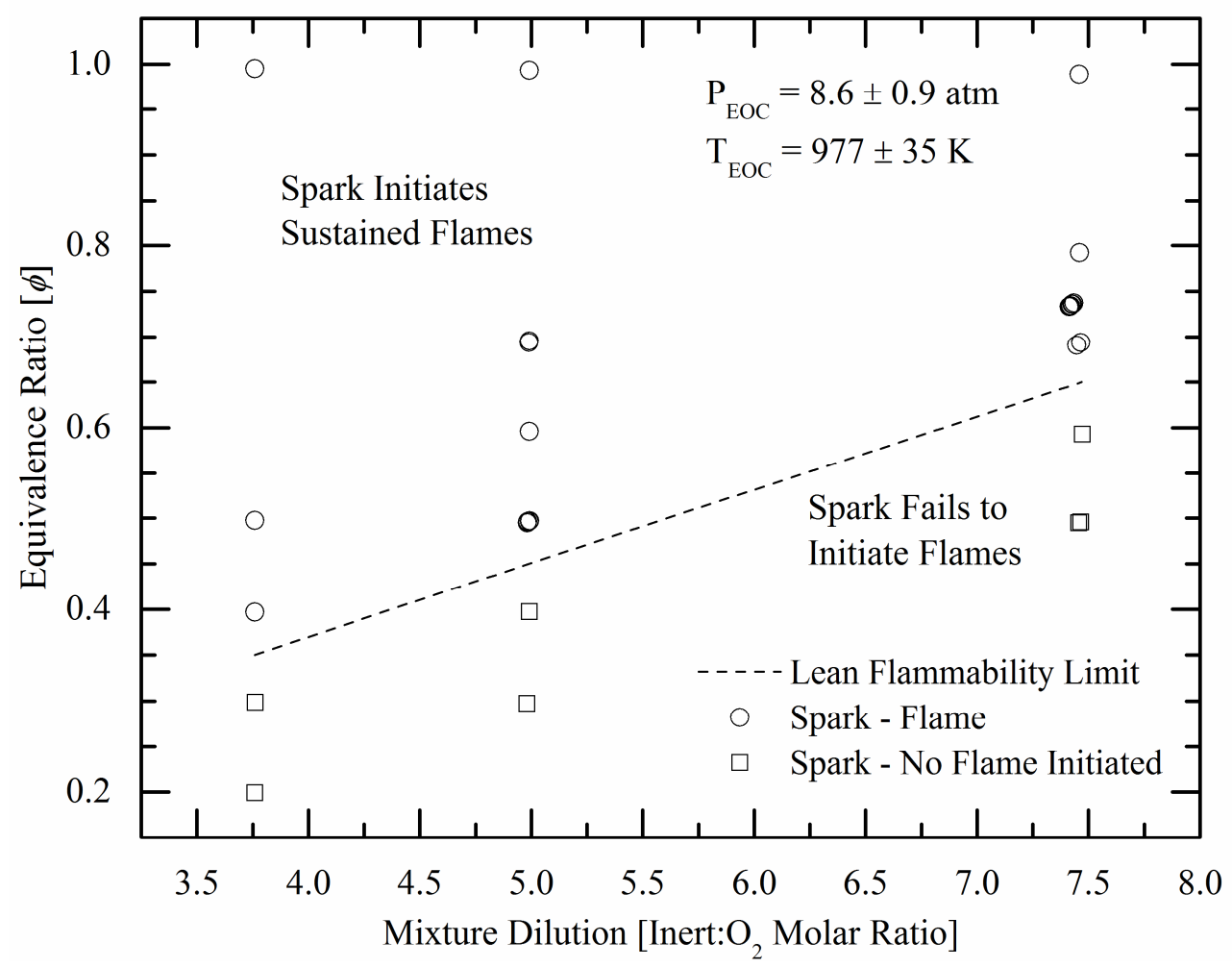

Figure 6. Summary of the experimental results for lean flammability limits as a function of dilution. 


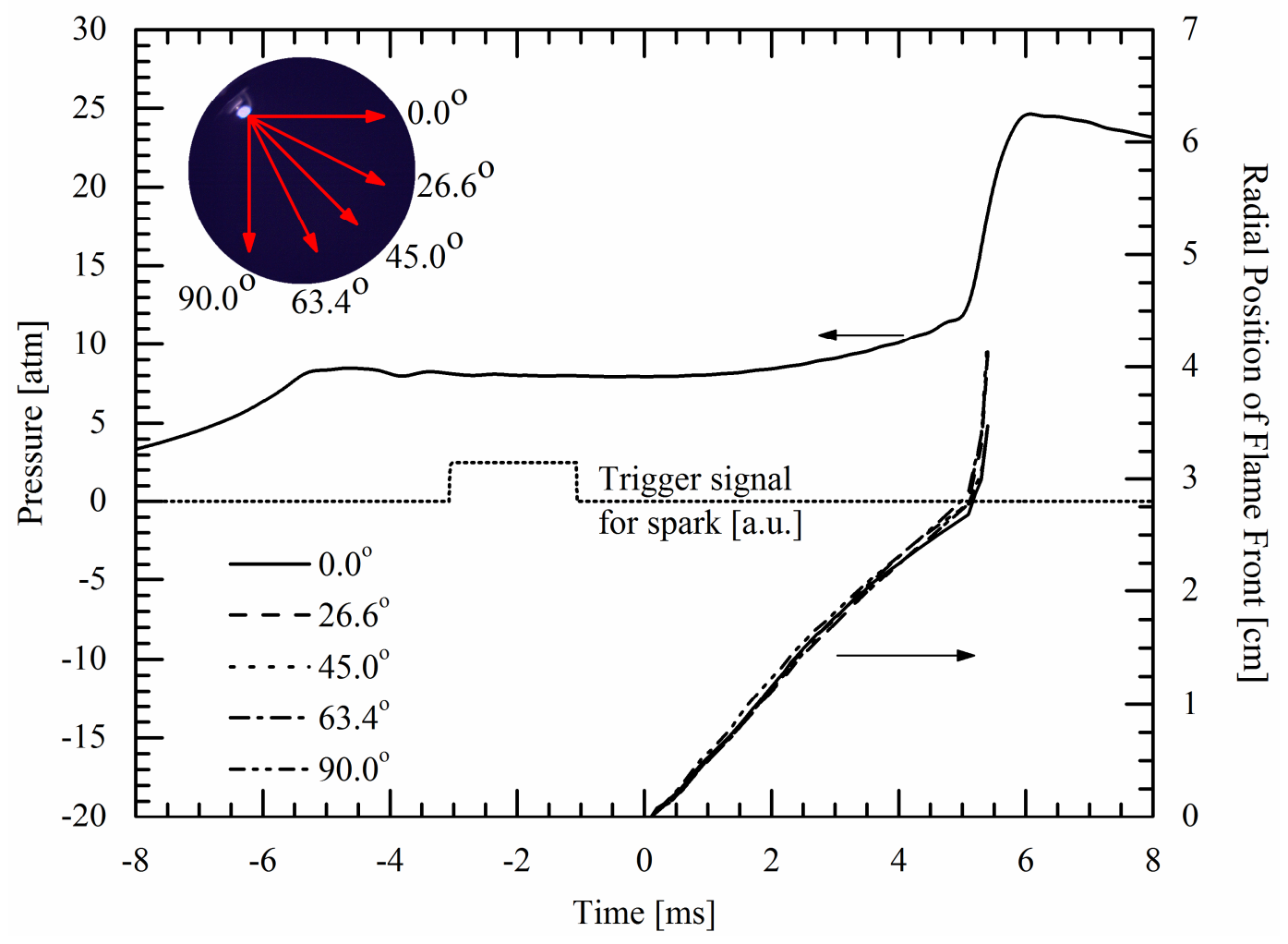

Figure 7. Time histories of the flame position as determined from the high-speed imaging data of the experimental results of Figure $2\left(\phi=0.99\right.$, inert to $\mathrm{O}_{2}$ ratio $=4.99, T_{E O C}=976 \mathrm{~K}$, and $P_{E O C}=$ $8.4 \mathrm{~atm})$. The pressure time history and spark plug trigger signals are provided for reference. Time $\mathrm{t}=0 \mathrm{~ms}$ corresponds to the first observation of the spark plasma. Measurements were made along five vectors with a common origin (set as the center of the spark plasma) as shown in the inset. 


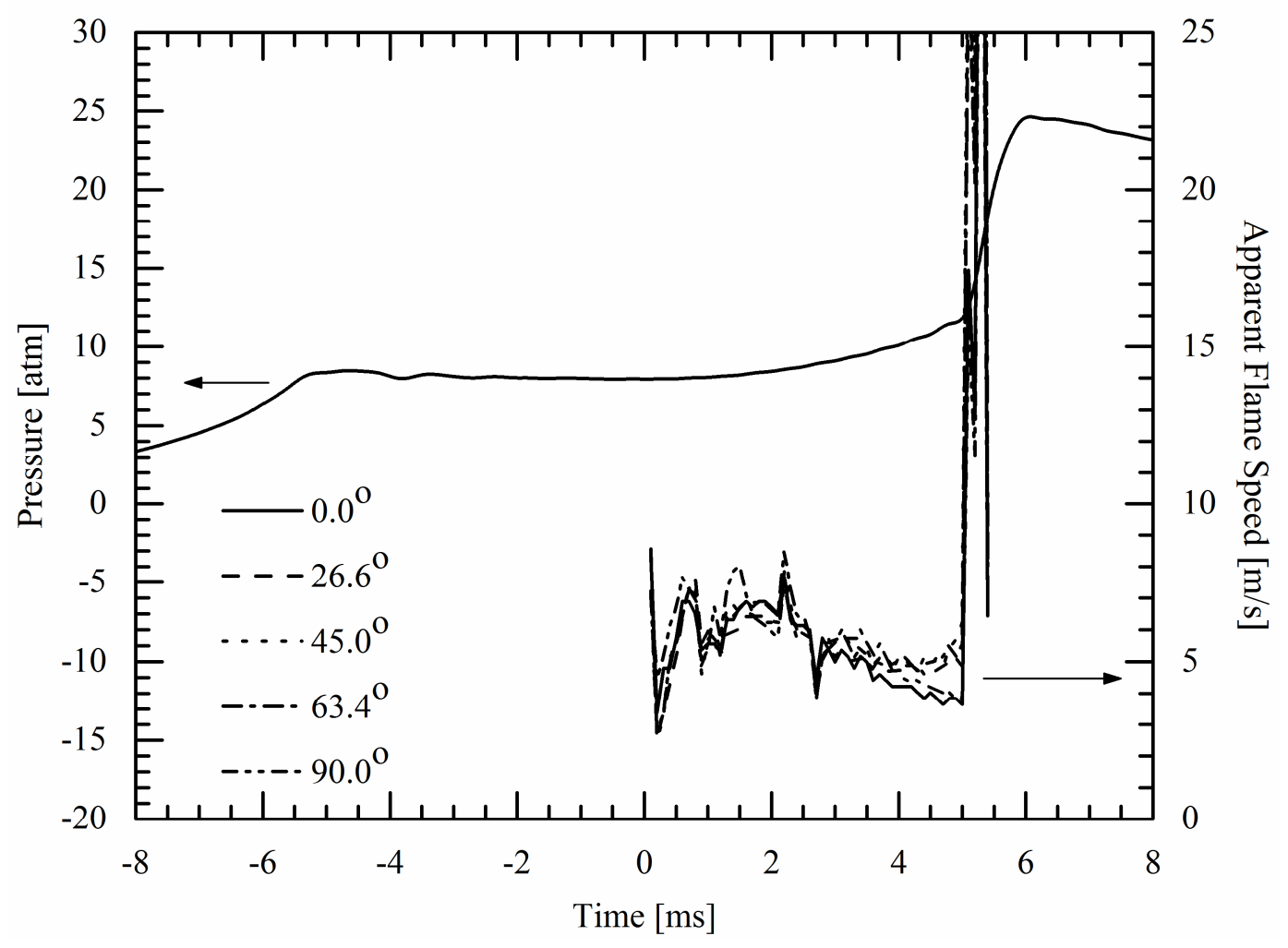

Figure 8. Results for apparent flame speed calculated using the derivative of the corresponding radial position data presented in Figure 7. Time $t=0.0 \mathrm{~ms}$ corresponds to the first observation of the spark plasma. The measurements are for the five trajectories presented in Figure 7. 


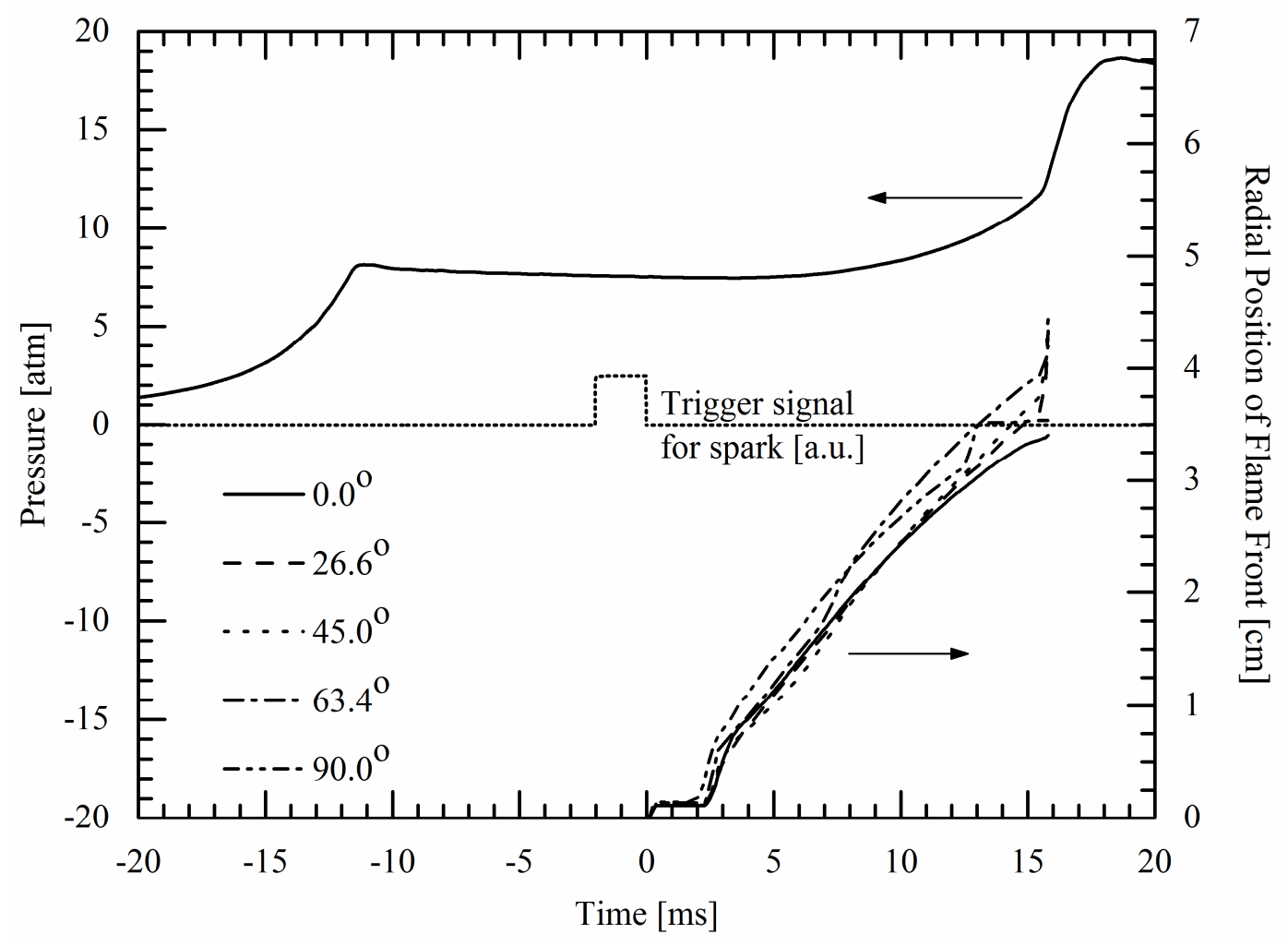

Figure 9. Time history of the flame position as determined from the high-speed imaging data of the experimental results of Figure $3\left(\phi=0.7\right.$, inert to $\mathrm{O}_{2}$ ratio $=4.99, T_{E O C}=942 \mathrm{~K}$, and $P_{E O C}=$ $8.1 \mathrm{~atm})$. The corresponding pressure time history and spark trigger signal are shown for reference. 


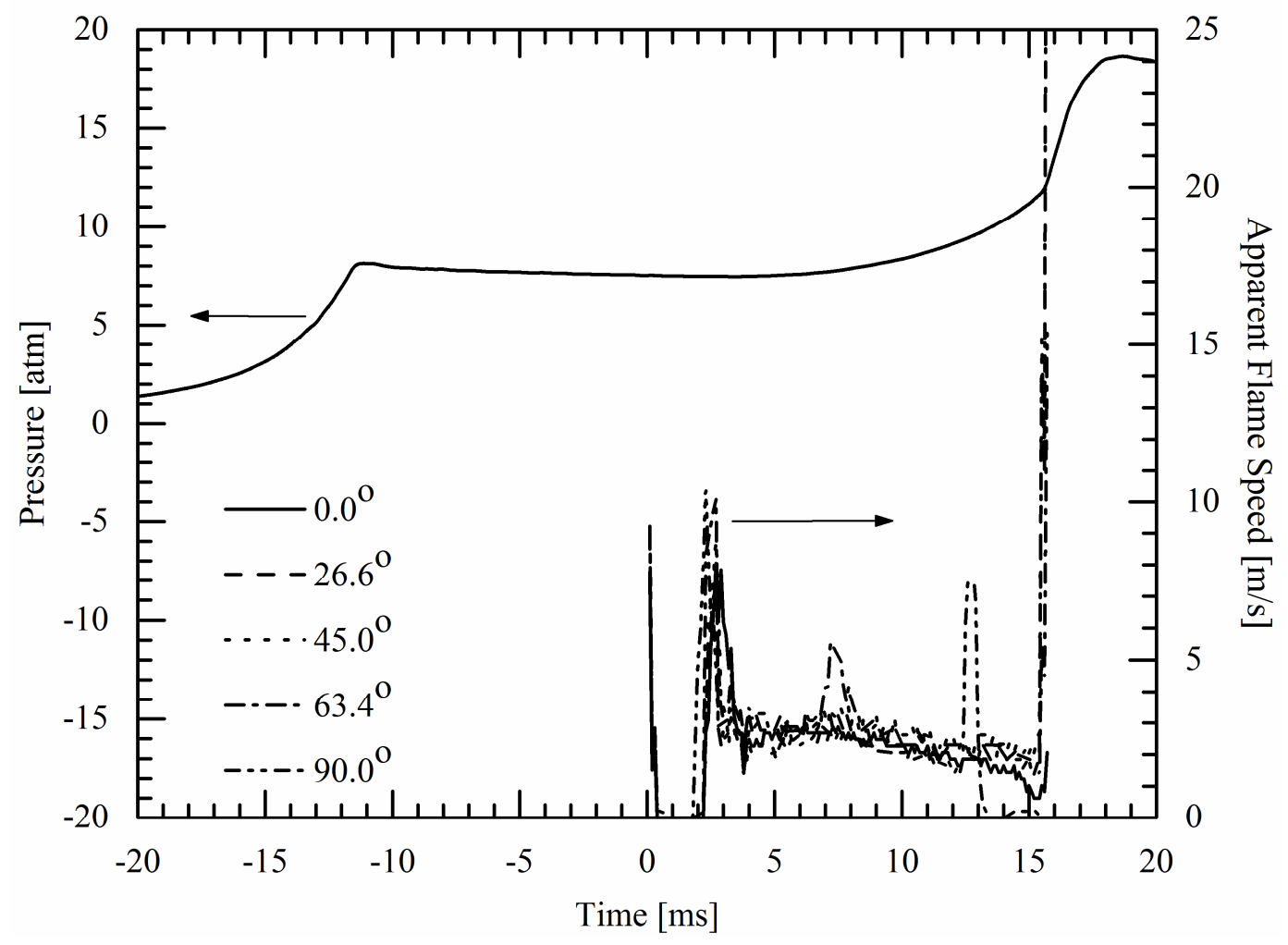

Figure 10. Results for apparent flame speed calculated using the derivative of the corresponding radial position data presented in Figure 9. 


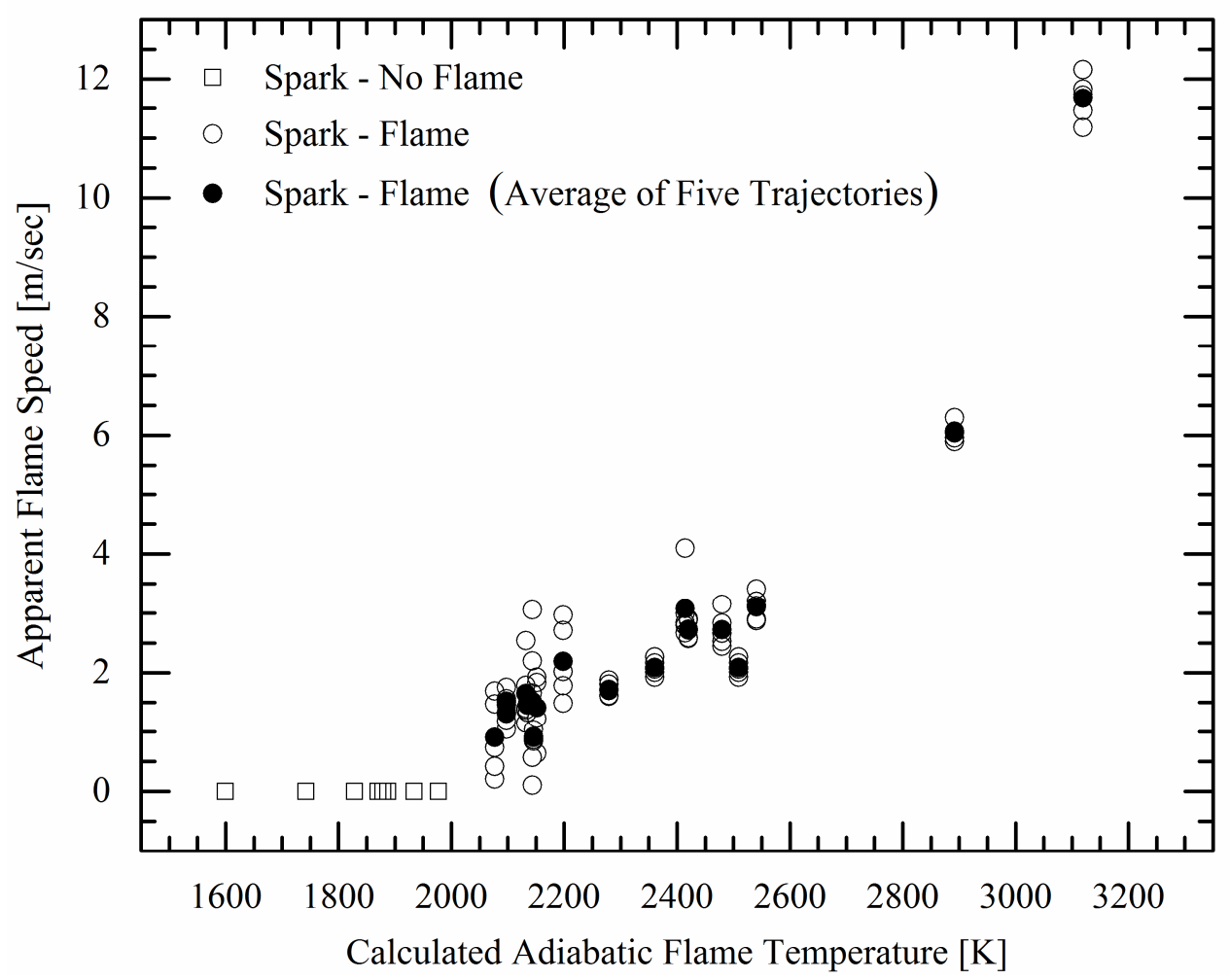

Figure 11. Experimental measurements of the average flame propagation rates as a function of the theoretical adiabatic flame temperature. The open symbols are the average propagation rates along each of the measurement vectors shown in the inset of Figure 7. The solid symbols are the overall averages for each experiment. 


\section{References}

[1] G.A. Lavoie, E. Ortiz-Soto, A. Babajimopoulos, J.B. Martz, D.N. Assanis, Int. J. Eng. Res. 14 (2012) 260-278.

[2] J.E. Dec, Proc. Combust. Inst. 32 (2009) 2727-2742.

[3] A.M.K.P. Taylor, Energy Policy 36 (2008) 4657-4667.

[4] A.C. Alkidas, Energy Conv. Man. 48 (2007) 2751-2761.

[5] M. Yao, Z. Zheng, H. Liu, Prog. Energy Combust. Sci. 35 (2009) 398-437.

[6] L. Manofsky, J. Vavra, A. Babajimopoulos, D.N. Assanis, SAE 2011-01-1179, 2011.

[7] B.T. Zigler, P.E. Keros, K.B. Helleberg, M. Fatouraie, Dim. Assanis, M.S. Wooldridge, Int. J. Eng. Res. 12 (2011) 353-375.

[8] J. P. Szybist, E. Nafziger, A. Weall, SAE 2010-01-2172, 2010.

[9] F. Matekunas, S, Proc. Combust. Inst. 17 (1979) 1283-1294.

[10] M. Kono, S. Shiga, S. Kumagai, K. Iinuma, Combust. Flame 54 (1983) 33-47.

[11] S. Shiga, S. Ozone, H.T.C. Machacon, T. Karasawa, H. Nakamura, T. Ueda, N. Jingu, Z. Huang, M. Tsue, M. Kono, Combust. Flame 129 (2002) 1-10.

[12] S. Shiga, M. Araki, T. Obokata, Z. Huang, H. Ishii, T. Ueda, M. Tsue, M. Kono, SAE 2005-26-352, 2005.

[13] A. Villela, J. Egúsquiza, J. Machado, S. Braga, SAE 2011-36-0349, 2011.

[14] S.M. Walton, X. He, B.T. Zigler, M.S. Wooldridge, A. Atreya, Combust. Flame 150 (2007) 246-262.

[15] X. He, M.T. Donovan, B.T. Zigler, T.R. Palmer, S.M. Walton, M.S. Wooldridge, A. Atreya, Combust. Flame 142 (2005) 266-275.

[16] X. He, B.T. Zigler, S.M. Walton, M.S. Wooldridge, A. Atreya, Combust. Flame 145 (2006) 
$552-570$.

[17] X. He, S.M. Walton, B.T. Zigler, M.S. Wooldridge, A. Atreya, Int. J. Chem. Kinet. 39 (2007) 498-517.

[18] M.T. Donovan, X. He, B.T. Zigler, T.R. Palmer, M.S. Wooldridge, A. Atreya, Combust. Flame 137 (2004) 351-365.

[19] B.J. McBride, S. Gordon, M.A. Reno, Coefficients for Calculating Thermodynamic and Transport Properties of Individual Species, NASA Technical Memorandum 4513, National Aeronautics and Space Administration, 1993.

[20] D.M.A. Karwat, S. Wagnon, P.D. Teini, M.S. Wooldridge, J. Phys. Chem. A 115 (2011) 4909-4921.

[21] S.W.Wagnon, M.S. Wooldridge, Combust. Flame (2013), http://dx.doi.org/10.1016/j.combustflame.2013.09.022

[22] T. Tahtouh, F. Halter, C. Mounaïm-Rousselle, Combust. Flame 156 (2009) 1735-1743.

[23] A.P. Kelley, J.K. Bechtold, C.K. Law, J. Fluid Mech. 691 (2012) 26-51.

[24] Z. Chen, M.P. Burke, Y. Ju, Proc. Combust. Inst. 32 (2009) 1253-1260.

[25] M. Mehl, H.J. Curran, W.J. Pitz, C.K. Westbrook Proc. Combust. Inst. 33 (2011) 193-200. 